\title{
Transabdominal ultrasonographic determination of pregnancy and fetal viability in buffalo cows
}

\author{
D.M. Aziz ${ }^{\circledR}$ and B.D. Al-Watar
}

Department of Surgery and Theriogenology, College of Veterinary Medicine, University of Mosul, Mosul, Iraq

Article information

\section{Article history:}

Received April 01, 2021

Accepted May 20, 2021

Available online December 19, 2021

\section{Keywords:}

Buffalo

Pregnancy

Fetal viability

Transabdominal

Ultrasonography

\section{Correspondence:}

D.M. Aziz

dhaferaziz@daad-alumni.de

\begin{abstract}
The study was conducted to evaluate the application of transabdominal ultrasonography for the determination of pregnancy and fetal viability in Iraqi buffaloes. Thirty-two buffaloes at different periods of gestation were included. The buffaloes were palpated transrectally and transabdominal ultrasonography was applied to determine the pregnancy and fetal viability status. The accuracy, sensitivity, specificity, the positive and negative predictive value of transrectal palpation were 93.7, 100, 83.3, 90.9, and 100\%, and for transrectal palpation were $78.1,100,58.8,68.2$, and $100 \%$, respectively. The values of accuracy and specificity in the first trimester obtained by transabdominal ultrasonography were lower than those obtained by rectal palpation (66.6 vs. $94.4 \%$ and 62.5 vs. $90.9 \%$ ), whereas the same values of accuracy and specificity were at second and third trimesters. Notwithstanding the values of the transrectal palpation and transabdominal ultrasonography sensitivity were $100 \%$ in the three trimesters of buffalo's gestation. At the first trimester of gestation, transabdominal ultrasonography required more time in comparison to transrectal palpation to get the final decision. Conversely, transrectal palpation required more time than transabdominal ultrasonography to diagnose the pregnant buffalos which were at the second and third trimesters of gestation. The transabdominal ultrasonography pregnancy diagnosis in the third trimester was faster than at the second and first trimester, a highly significant $(\mathrm{P}<0.001)$ negative correlation was reported between the time required for pregnancy diagnosis and the gestation age. It can be concluded that the transabdominal is a practical approach of ultrasonography for pregnancy diagnosis and determination of fetal viability in buffalo cows especially at the second and third trimesters of gestation.
\end{abstract}

DOI: 10.33899/ijvs.2021.129858.1694, (OAuthors, 2022, College of Veterinary Medicine, University of Mosul.

This is an open access article under the CC BY 4.0 license (http://creativecommons.org/licenses/by/4.0/).

\section{Introduction}

Buffaloes are breed in Iraq for milk and meat production. A large number of these animals are breed individually or in small herds. Many buffaloes have no reproductive information such as the date of estrus, service, and pregnancy. Therefore, numerous buffalo cows are presented to the clinics at different periods of gestation for estimation of pregnancy status. Currently, there are two popular methods for pregnancy diagnosis in buffalo cows: transrectal palpation and transrectal ultrasonography. Transrectal palpation is the oldest and most widely method used for pregnancy diagnosis in cattle and buffaloes (1). Transrectal ultrasonography is considered a practical, reliable, and more accurate method for pregnancy diagnosis in domestic animals. It provides the possibility of early pregnancy determination and monitoring of the development and viability of the embryo (2). In both methods, transrectal palpation and ultrasonography, there are sometimes difficulties in pregnancy diagnosis because of the large size of the abdominal cavity and pregnant uterine horns go down. In such cases, the pregnancy diagnosis and fetal viability determination cannot be recognized especially at the second trimester of gestation (3). Also, transrectal invasive is 
considered stressful (4) and rectal mucosa bleeds easily because it's more fragile in the buffalos compared to cattle (5). Several studies for the application of the ultrasonographic technique for the determination of pregnancy in buffaloes have been conducted. The most of studies were adopted the transrectal application of ultrasonography (6-12). A few and limited studies have adopted the transabdominal ultrasonography for evaluation of pregnancy in large ruminant $(3,13-15)$. While only one study was applicated the transabdominal ultrasonography for pregnancy diagnosis in buffaloes (16). The present study was designed to evaluate an alternative approach for pregnancy diagnosis and determination of fetal viability in Iraqi buffaloes. The transabdominal ultrasonography was evaluated to reduce the probability of misdiagnosis and to avoid the harmful effect of transrectal invasive.

\section{Materials and methods}

\section{Animals}

In this study, thirty-two buffaloes (aged between three to six years) were presented to the Clinic of the Veterinary Medicine College, University of Mosul, Mosul, Iraq, for pregnancy verification. The presented buffalo cows were at different periods of gestation (according to the information of buffalo's owner that gave a date of insemination). Thirteen buffaloes were in the first trimester (1-100 days), eight buffaloes were in the second trimester (101-200 days), and eleven buffaloes were in the third trimester (more than 201 days) of gestation.

\section{Pregnancy diagnosis}

Firstly, the buffalo cows were palpated transrectally for determination of pregnancy, the screening was performed by a clinician that has high experience in transrectal pregnancy diagnosis. After that, a transabdominal ultrasonographic examination was applied to determine the pregnancy status and to determine the fetal viability. The buffalos were examined in a standing position using a B-mode ultrasound scanner equipped with a $3.5 \mathrm{MHz}$ sector transducer (KAI XIN, KX5100, Zhou Kaixin Electronic Instrument Co. Ltd, China). The transabdominal examination was done by applying the probe on the ventral abdominal wall after putting the gel without clipping or shaving. The examination area (Figure 1) was located on the right ventral abdominal wall, around the base of the udder ventrally, and the area between the stifle fold and abdominal wall dorsally (3). The animals were considered pregnant if the anechogenic areas of the fluid-filled uterus (Figure 2) and placentomes (Figure 3 ) were observed, while the fetal viability determination was mainly dependent on the observation of the heartbeat or fetal movement (Figure 4) (3).

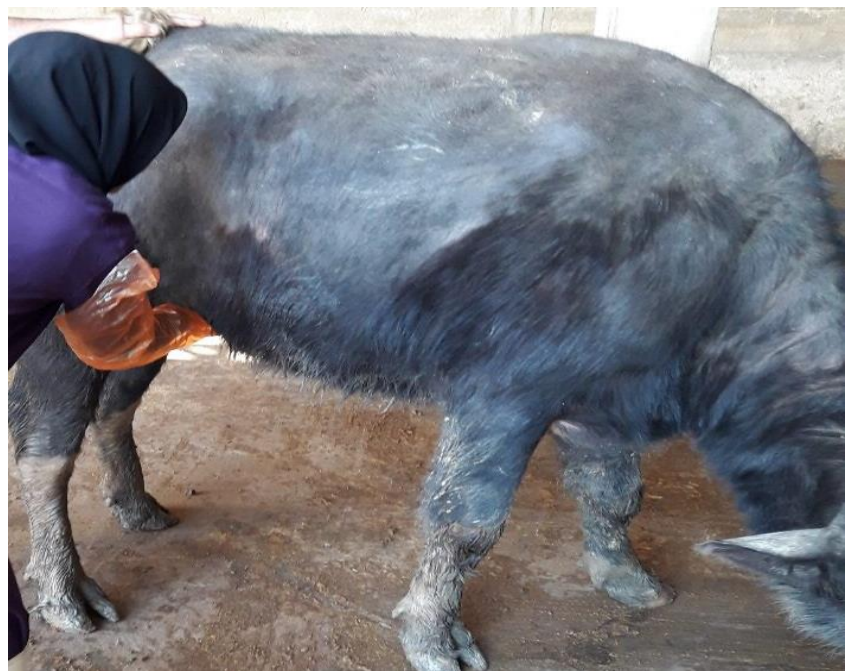

Figure 1: The transabdominal ultrasonographic approach for pregnancy diagnosis and determination of fetal viability in buffalo cows.

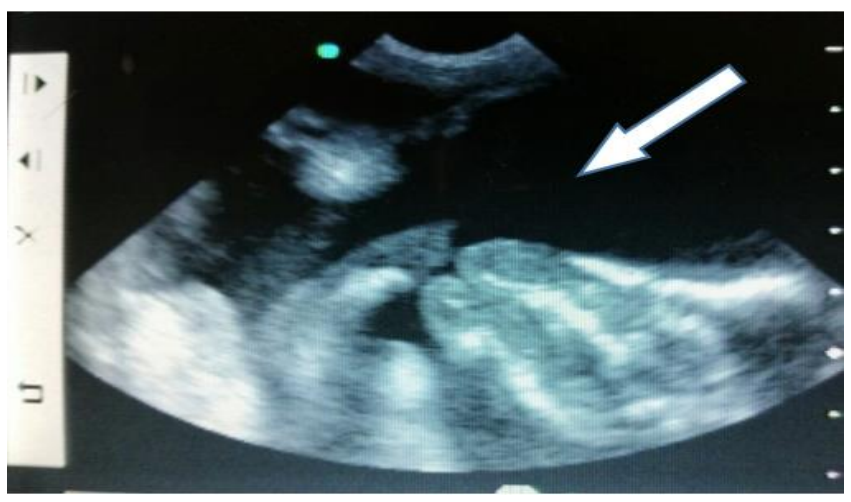

Figure 2: Transabdominal ultrasonographic image of buffalo at the seventh month of pregnancy, white arrow: anechogenic areas of the fluid-filled uterus.



Figure 3: Transabdominal ultrasonographic image of buffalo at the sixth month of pregnancy, white arrow: placentome. 




Figure 4: Transabdominal ultrasonographic image of buffalo at the fifth month of pregnancy, white arrow: the heart.

In both transrectal palpation and transabdominal ultrasonography, the time required to access the final diagnosis has been calculated. The accuracy of pregnancy determination was measured by dividing the summation of the true positive results and the true negative results on all examined animal's $x 100$. The sensitivity was calculated by dividing the number of buffaloes that the true positive pregnant diagnosed on the summation of the true positive and the false negative pregnant diagnosed buffaloes x 100 . The specificity of the diagnosis method was calculated by dividing the number of buffaloes that the true negative diagnosed on the summation of animals that the true negative and the false positive diagnosed $\mathrm{x} 100$. The positive predictive value was calculated by dividing the number of buffaloes that the true positive pregnant diagnosed on the summation of the true positive and the false positive diagnosed buffalo's x 100. The negative predictive value of the diagnosis method was calculated by dividing the number of buffaloes that the true negative diagnosed on the summation of animals that the true negative and the false negative pregnant diagnosed x 100 (17).

\section{Statistical analysis}

The data of accuracy, sensitivity, specificity, positive predictive value, and negative predictive value were compared using the Chi-square test. Data of time that required for pregnancy diagnosis were presented as mean \pm $\mathrm{SE}$, and compared by T-test. The relationship between the time and gestation period was analyzed using the Pearson correlation coefficients. The statistical analyses were conducted by SigmaStat (Jandel scientific software V3.1). $\mathrm{P}<0.05$ was considered statistically significant.

\section{Results}

Results of rectal palpation and ultrasonographic examination of the buffaloes were summarized in Table 1 . Out of thirty-two buffaloes, twenty-two buffaloes were pregnant and the other ten buffaloes were non-pregnant. The results of transrectal palpation of pregnant buffaloes included that twenty buffaloes were true positive diagnosed and two buffaloes were false positive diagnosed. Whereas all non-pregnant buffaloes were true negative diagnosed and no buffaloes were false negative diagnosed. The accuracy, sensitivity, specificity, positive predictive value, and negative predictive value of transrectal palpation were 93.7, $100,83.3,90.9$, and $100 \%$, respectively.

On the other hand, the results of transabdominal ultrasonography of pregnant buffaloes included that fifteen buffaloes were true positive diagnosed and seven buffaloes were false positive diagnosed. While examination of nonpregnant buffaloes resulted in the same results as transrectal palpation. The accuracy, sensitivity, specificity, positive predictive value, and negative predictive value of transrectal palpation were $78.1,100,58.8,68.2$, and $100 \%$, respectively.

Table 2 presented the accuracy, sensitivity, and specificity of pregnancy diagnosis obtained by rectal palpation and transabdominal ultrasonography at the different trimester of gestation in buffalo cows. The values of accuracy and specificity in the first trimester that obtained by transabdominal ultrasonography were lower than those that obtained by rectal palpation ( 66.6 vs. $94.4 \%$ and 62.5 vs. $90.9 \%$ ), whereas the same values of accuracy and specificity were obtained by rectal palpation and transabdominal ultrasonography at second and third trimesters. Notwithstanding the values of the transrectal palpation and transabdominal ultrasonography sensitivity were $100 \%$ in the three trimesters of buffalo's gestation.

Table 3 shows the time required to obtain the final decision of pregnancy diagnosis for buffaloes that were examined by transrectal palpation and transabdominal ultrasonography. Non-pregnant buffalos that were examined by transabdominal ultrasonography were diagnosed faster $(\mathrm{P}<0.01)$ than those which were examined by transrectal palpation $(5.9 \pm 1.4$ vs. $9.3 \pm 1.6 \mathrm{~min})$. At the first trimester of gestation, transabdominal ultrasonography required more time in comparison to transrectal palpation to get the final decision $(9.1 \pm 1.8$ vs. $7.9 \pm 2.0 \mathrm{~min})$.

Conversely, transrectal palpation required more time than transabdominal ultrasonography to diagnose the pregnant buffalos which were at second and third trimesters of gestation $(8.0 \pm 2.0$ vs. $7.0 \pm 2.7$ and $5.9 \pm 1.4$ vs. $5.1 \pm$ $0.3 \mathrm{~min})$. The transabdominal ultrasonography in the third trimester was faster than at the second and first trimester, a highly significant $(\mathrm{P}<0.001)$ negative correlation $(\mathrm{r}=-0.812)$ was reported between the time required for pregnancy diagnosis and the gestation age.

The transabdominal approach of ultrasonography gave an ability to monitor fetal viability. The positive predictive values of fetal viability obtained at the $1^{\text {st }}, 2^{\text {nd }}$ and $3^{\text {rd }}$ trimesters of gestation were 23.1, 100 and 90.9\%, respectively. The overall positive predictive value for the determination of fetal viability was $65.6 \%$ (Figure 4). 
Table 1: Results of rectal palpation and transabdominal ultrasonography for pregnancy diagnosis in buffalos

\begin{tabular}{llcc}
\hline \multirow{2}{*}{ Diagnosis } & \multirow{2}{*}{ No. of buffalos } & \multicolumn{2}{c}{ Method of examination } \\
\cline { 3 - 4 } & 22 & Rectal palpation & Transabdominal ultrasonography \\
\hline Pregnant & $220^{\mathrm{a} / 2}$ & $15^{\mathrm{b}} / 7^{\mathrm{b}}$ \\
Non-pregnant & 10 & $10^{\mathrm{c}} / 0^{\mathrm{d}}$ & $10^{\mathrm{c}} / 0^{\mathrm{d}}$ \\
Accuracy $^{(\mathrm{a}+\mathrm{c}) /(\mathrm{a}+\mathrm{b}+\mathrm{c}+\mathrm{d}) * 100}$ & & $93.7 \%$ & $78.1 \%$ \\
Sensitivity $^{\mathrm{a} /(\mathrm{a}+\mathrm{d}) * 100}$ & & $100 \%$ & $100 \%$ \\
Specificity $^{\mathrm{c} /(\mathrm{c}+\mathrm{b}) * 100}$ & $83.3 \%$ & $58.8 \%$ \\
Positive predictive value $^{\mathrm{a} /(\mathrm{a}+\mathrm{b})^{*} 100}$ & & $90.9 \%$ & $68.2 \%$ \\
Negative predictive value $^{\mathrm{c}(\mathrm{c}+\mathrm{d}) * 100}$ & & $100 \%$ & $100 \%$ \\
\hline
\end{tabular}

${ }^{a}$ number of cows were true positive diagnosed, ${ }^{b}$ number of cows were false positive diagnosed,

${ }^{c}$ number of cows were true negative diagnosed, ${ }^{\mathrm{d}}$ number of cows were false negative diagnosed.

Table 2: Accuracy, sensitivity and specificity of buffalo's pregnancy diagnosis that obtained by rectal palpation and transabdominal ultrasonography at different trimester of gestation

\begin{tabular}{lcccccc}
\hline \multirow{2}{*}{ Pregnancy period } & \multicolumn{2}{c}{ Accuracy $(\%)$} & \multicolumn{2}{c}{ Sensitivity (\%) } & \multicolumn{2}{c}{ Specificity (\%) } \\
\cline { 2 - 6 } & RP & TU & RP & TU & RP & TU \\
\hline $1^{\text {st }}$ trimester & 94.4 & 66.6 & 100 & 100 & 90.9 & 62.5 \\
$2^{\text {nd }}$ trimester & 93.3 & 93.3 & 100 & 100 & 90.9 & 90.9 \\
$3^{\text {rd }}$ trimester & 100 & 100 & 100 & 100 & 100 & 100 \\
\hline
\end{tabular}

RP: Rectal palpation, TU: Transabdominal ultrasonography.

Table 3: Time required for rectal palpation and transabdominal ultrasonography to make a decision for pregnancy diagnosis in buffalo cows

\begin{tabular}{lcc}
\hline \multirow{2}{*}{ Pregnancy status of buffalo cows } & \multicolumn{2}{c}{ Time required for pregnancy diagnosis (min) } \\
\cline { 2 - 3 } & Rectal palpation & Transabdominal ultrasonography \\
\hline Non-pregnant & $9.3 \pm 1.6$ & $5.9 \pm 1.4^{*}$ \\
$1^{\text {st }}$ trimester of pregnancy & $7.9 \pm 2.0$ & $9.1 \pm 1.8^{\mathrm{NS}}$ \\
$2^{\text {nd }}$ trimester of pregnancy & $8.0 \pm 2.0$ & $7.0 \pm 2.7^{\mathrm{NS}}$ \\
$3^{\text {rd }}$ trimester of pregnancy & $5.9 \pm 1.4$ & $5.1 \pm 0.3^{\mathrm{NS}}$ \\
\hline
\end{tabular}

* Significant at $\mathrm{P}<0.01,{ }^{\mathrm{NS}}$ No significant.

Table 4: Results of transabdominal ultrasonography for the determination of fetal viability in buffalo cows

\begin{tabular}{|c|c|c|c|c|}
\hline \multirow[t]{2}{*}{ Pregnancy period } & \multirow{2}{*}{ No. of pregnant buffalo } & \multicolumn{2}{|c|}{ Determination of fetal viability } & \multirow{2}{*}{ Positive predictive value $(\%)$} \\
\hline & & Positive & Negative & \\
\hline $1^{\text {st }}$ trimester & 13 & 3 & 10 & $23.1^{\mathrm{a}}$ \\
\hline $2^{\text {nd }}$ trimester & 8 & 8 & 0 & $100^{\mathrm{b}}$ \\
\hline $3^{\text {rd }}$ trimester & 11 & 10 & 1 & $90.9^{\mathrm{b}}$ \\
\hline Total & 32 & 21 & 11 & $65.6 \%$ \\
\hline
\end{tabular}

$\overline{\mathrm{a}, \mathrm{b}}$ the different letter refer to significant differences $(\mathrm{P}<0.05)$.

\section{Discussion}

Rectal palpation was and is still the standard method of pregnancy diagnosis in cattle and other large animals. There are two main reasons for designing the current study, the first one was, pregnancy diagnosis in buffalo cows by rectal palpation or transrectal ultrasonography sometimes is difficult due to the large size of the body and the abdominal cavity, especially at the second trimester (5-6 months) of gestation (18). The second reason was, the rectal palpation is painful and causes a stress reaction that increases the circulating cortisol (4). Therefore, our study was conducted to evaluate an alternative procedure (transabdominal ultrasonography) for pregnancy diagnosis in buffalo cows.

Results of the current work showed that the application of transabdominal ultrasonography is an accurate and practical procedure for pregnancy diagnosis in buffaloes especially those at the second and third trimester of 
gestation. These results were obtained due to the location of the pregnant uterus at this period of gestation. The uterus is becoming large and heavy and lying down in the lower abdominal cavity (18), and it is becoming close over the area of examination which was applied in this study. Similar results of our study were obtained by Aziz (3) when the cows were examined at the fourth to sixth months of gestation using the transabdominal ultrasonography.

At the second and third trimesters of buffalo cow gestation, both transabdominal ultrasonography and rectal palpation gave equal values of accuracy, sensitivity, and specificity. While the values of accuracy and specificity of transabdominal ultrasonography at the first trimester were lower than those were obtained by rectal palpation. The lower values of accuracy and specificity at the first trimester were obtained due to the location of the pregnant uterus at this period. The gravid uterus is located in the pelvic cavity or upper abdominal cavity at the first trimester of gestation (18). Whereas the area of examination in the current study was the lower part of the abdominal wall, therefore the uterus was not observed at the range of ultrasound images. An analogous result was reported in cows that examined transabdominaly (3).

Our results indicated that the pregnancy diagnosis using transabdominal ultrasonography became easier and faster by increasing gestation age. We obtained this result because the pregnant uterus is approaching the ventral abdominal wall by increasing the duration of the pregnancy (19). This approaching decreases the distance between the uterine wall and the ultrasonographic probe, so we get the result faster. A similar observation was recorded in small $(20,21)$ and large ruminants when examined transabdominaly in a standing position (3).

In comparison to the rectal palpation, transabdominal ultrasonography provided screening of fetal viability, because this method gave a possibility to monitor the fetus movement and other signs of fetal viability especially the heartbeat. The positive predictive value of the determination of fetal viability at the $2^{\text {nd }}$ and $3^{\text {rd }}$ trimester of gestation was higher than the value at the first trimester of gestation. The lower value of positive predictive at the first trimester was obtained because the fetus and gravid uterus are located out the range of the ultrasonographic image. This finding supports the conclusion of Aziz (3) for the determination of fetal viability in pregnant cows.

The transabdominal approach of ultrasonography that applicate in the current study for pregnancy diagnosis in buffalo cows has many advantages over the transrectal palpation, these include; rectal evacuation is not needed, avoid the possibility of rectal injury, limitation of animal restriction that required for animal examination (3).

\section{Conclusion}

Transabdominal is a practical approach of ultrasonography for pregnancy diagnosis and determination of fetal viability in buffalo cows especially at the second and third trimesters of gestation.

\section{Acknowledgments}

The authors would like to thank the College of Veterinary Medicine, University of Mosul, Mosul, Iraq, for supporting this work.

\section{Conflict of interest}

There is no conflict of interest.

\section{References}

1. Momont H. Rectal palpation: Safety issues. Bovine Practitioner. 1990;25:122-123. 10.21423/bovine-vol0no25p122-123

2. Awasthi M, Abhishek K, Kavani F, Siddique G, Dhami AJ. Early pregnancy diagnosis in water buffaloes using transrectal ultrasonography. Indian Anim Reprod. 2016;32:43-46.

3. Aziz DM. Clinical application of a rapid and practical procedure of transabdominal ultrasonography for determination of pregnancy and fetal viability in cows. Asian Pacific J Reprod. 2013;2:326-329. 10.1016/S2305-0500(13)60172-4.4

4. Cingi CC, Baser DF, Karafakioglu YS, Fidan AF. Stress response in dairy cows related to rectal examination. Acta Sci Vet. 2012;40:1053. [available at]

5. Purohit GN. Methods of pregnancy diagnosis in domestic animals: The current status. Web Med Central Reprod. 2010;1:1-26. 10.9754/journal.wmc.2010.001305

6. Pawshe CH, Appa Rao KBC, Totey SM. Ultrasonographic imaging to monitor early pregnancy and embryonic development in the buffalo (Bubalus bubalis). Theriogenol. 1994;41:697-709. 10.1016/0093691X(94)90179-M

7. Karen AM, Darwish S, Ramoun A, Tawfeek K, Van Hanh N, de Sousa $\mathrm{N}$ M. Accuracy of transrectal palpation for early pregnancy diagnosis in Egyptian buffaloes. Trop Anim Health Prod. 2010;43:5-7. 10.1007/s11250-010-9675-2

8. Ferreira JCP, Martin I, Irikura CR, Gimenes LU, Fujihara CJ, Jorge AM, Oba E. Ultrasonographic monitoring of early pregnancy development in Murrah buffalo heifers (Bubalus bubalis). Liv Sci. 2011;138:1-3. 10.1016/j.livsci.2010.12.017

9. Mutha Rao M, Uma Mahesh Y. Efficacy of different harvesting techniques on oocyte retrieval from buffalo ovaries. Buffalo Bulletin (Thailand). 2012;31:209-213. [available at]

10. Samir H, Badr H, Kandiel M, Lasheen M, Abo El-Maaty A, Eldawy M. Monitoring of early pregnancy fetometry in egyptian buffaloes using high frequency transrectal b-mode and color doppler ultrasonography. J Appl Vet Sci. 2017;2:17-22. 10.21608/javs.2017.62134

11. Ali A, Fahmy S. Ultrasonographic fetometry and determination of fetal sex in buffaloes (Bubalus bubalis). Anim Reprod Sci. 2008;106:90-99. 10.1016/j.anireprosci.2007.04.010

12. Naikoo M, Patel DM, Derashri HJ. Early pregnancy diagnosis by transrectal ultrasonography in Mehsana buffaloes (Bubalus bubalis). Buffalo Bulletin. 2013;32:120-125. [available at]

13. Lazim EH, Alrawi HM, Aziz DM. Relationship between gestational age and transabdominal ultrasonographic measurements of fetus and uterus during the 2 nd and 3rd trimester of gestation in cows. Asian Pacific $\mathbf{J}$ Reprod. 2016;5:326-330. 10.1016/j.apjr.2016.06.010 
14. Baska-Vincze B, Baska F, Szenci O. Transabdominal ultrasonographic evaluation of fetal well-being in the late-term mare and cow. Acta Vet Hung. 2014;62:439-51. 10.1556/AVet.2014.018. PMID:25410386

15. Buczinski S, Belanger AM, Fecteau G, Roy JP. Prolonged gestation in two Holstein cows: transabdominal ultrasonographic findings in late pregnancy and pathologic findings in the fetuses. J Vet Med Physiol Pathol Clin Med. 2007;54:624-626. 10.1111/j.14390442.2007.00985.x

16. Singh G, Chandolia R, Dutt R, Saini A, Dalal J, Malik R, Chhikara S. Trans-abdominal ultrasonography during second and third trimester in Murrah buffaloes. Int J Liv Res. 2017;7:174-185. 10.5455/ijlr.20170426104230

17. Silva E, Sterry RA, Kolb D, Mathialagan N, McGrath MF, Ballam JM, Fricke PM. Accuracy of a Pregnancy-associated glycoprotein ELISA to determine pregnancy status of lactating dairy cows twenty-seven days after timed artificial insemination. J Dairy Sci. 2007;90:4612-4622. 10.3168/jds.2007-0276

18. Ball PJH, Peters AR. Reproduction in cattle. $3^{\text {rd }}$ ed. USA: Blackwell Publishing Ltd; 2004. 56-78 p.

19. DesCoteaux L, Picard-Hagen N, Durocher J, Buczinski S, Colloton J, Chastant-Maillard S, Curran S. Bovine fetal development after 55 Days, fetal sexing, anomalies, and well - being. In: DesCôteaux L, Gnemmi G, Colloton J, editors. Practical atlas of ruminant and camelid reproductive ultrasonography. USA: Blackwell Publishing Ltd; 2010. 101-124 p.

20. Aziz DM, Lazim EH. Transabdominal ultrasonography in standing position for pregnancy diagnosis in Awassi ewes. Small Rumin Res. 2012;107:131-135. 10.1016/j.smallrumres.2012.05.007

21. Anwar M, Riaz A, Ullah N, Rafiq M. Use of ultrasonography for pregnancy diagnosis in balkhi sheep. Pak Vet J. 2008;28:144-146. [available at]

\section{فحص الحمل وحيوية الجنين باستخدام تقنية الأمواج فوق الصوتية عبر جدار البطن في

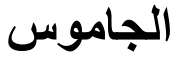

ظافر محمد عزيز و براء دريد الوتار

فرع الجراحة وعلم تتاسل الحيوان، كلية الطب البيطري، جامعة

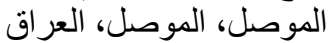



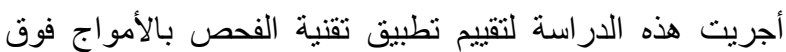



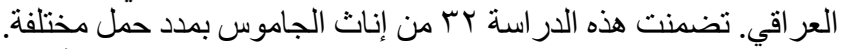

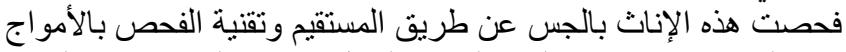

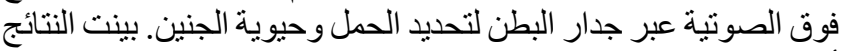



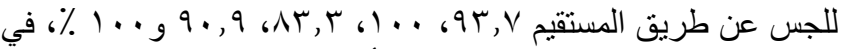

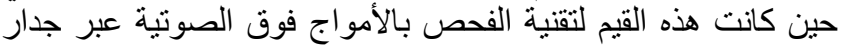

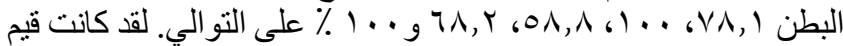

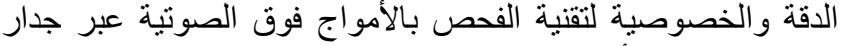

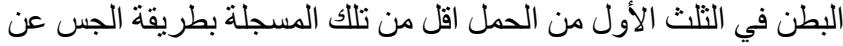

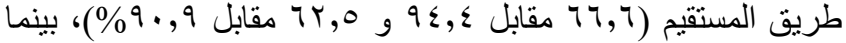

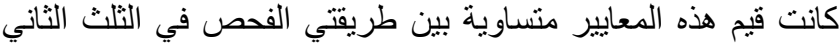

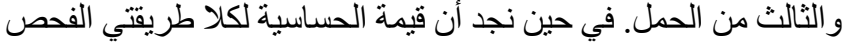

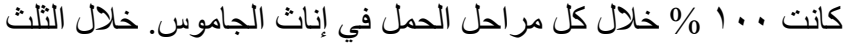

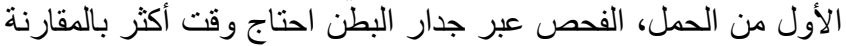

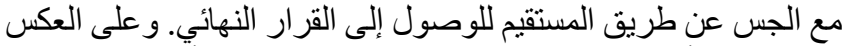

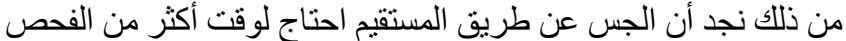

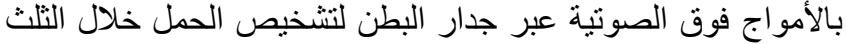

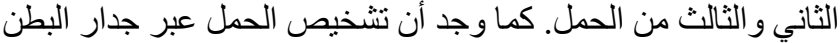







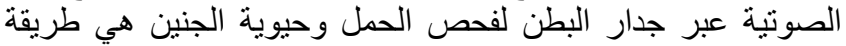
تطبيقية خصوصا" في الثلثين الأخيرين من الحمل. 